\title{
LESSONS FROM A CASE OF TUBAL TWIN PREGNANCY
}

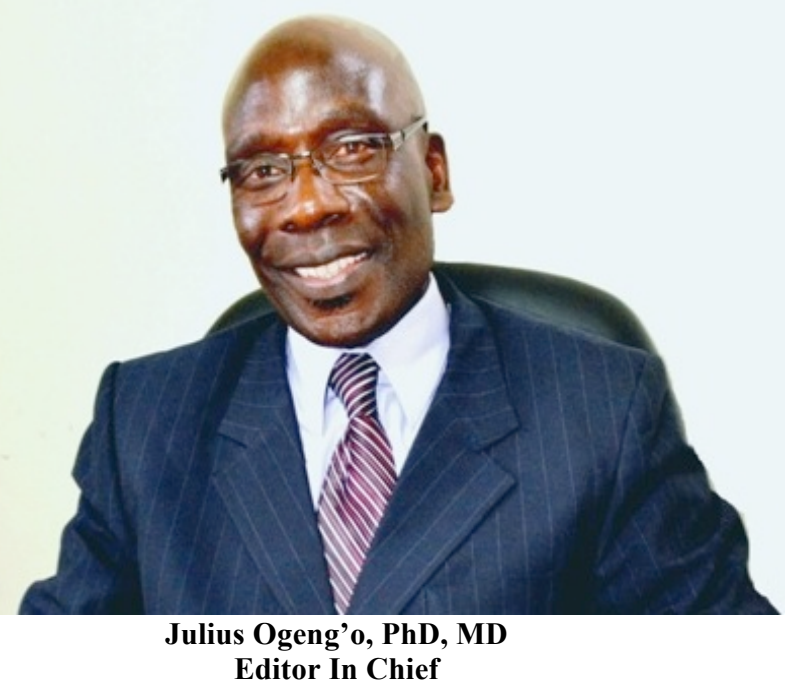

Department of Human Anatomy, University of Nairobi Email: jogengo@uonbi.ac.ke. Tel: $+254724837592$

Unilateral tubal twin pregnancy illustrates and amplifies fundamental phenomena in developmental and reproductive anatomy. Knowledge of this condition is also important to practicing obstetricians and gynaecologists because it may constitute a diagnostic challenge, management dilemma, complex ethical issues and increased risk for maternal morbidity and mortality (Benn et al., 2016). Previously considered a rare occurence, recent data suggest that the condition is not uncommon (Svirsky et al., 2010). Indeed, there are many reports (Vohra et al., 2014), including several from Sub-Saharan Africa (Makinde and Ogunniyi, 1990). The case reported by Pulei et al., in Anat J Afr 2017; 6 (1) reveals several unique features in the profile of risk factors, location, chorionicity and amnionicity, mode and time of presentation, condition of the tube, diagnosis and fetal viability. There was no evidence of the conventional risk factors (Sivalingam et al., 2011). This is consistent with several other reported cases where it occurred spontaneously (Abi Khalil et al., 2016). In the present case, however, the patient had multiple intramural and subserosal leiomyomata. Intramural myomata are known to disrupt uterine contractility which may interfere with transport of the ovum and hence predispose to ectopic pregnancy (Ajibade et al., 2012). It is probable, therefore, that this was the predisposing factor. Accordingly, it may be useful to monitor patients with uterine fibroids for potential to suffer ectopic pregnancy. Family history of twinning may have been useful, and is advocated, in view of the fact that it is one of the major predisposing factors.

In the case presented, the gestational sac was located in the fimbrial region, similar to that reported by Al - Quraan et al. (2007) and Adesule et al. (2010). The commonest site of tubal pregnancy is the ampulla followed by isthmus, with the fimbria being involved in only $5-11 \%$ of cases (Almeida, 2011). The location of the present case in the relatively unusual position is concordant with reports of twin pregnancy in rarer tubal sites like cornual (Ragsdale et al., 2014) and in other ectopic positions including the cervix (Pascual et al., 2001), ovary (Garg et al., 2009) and abdomen (Mpogoro et al., 
2013). This calls for thorough examination of the abdomen and pelvis when scanning for ectopic pregnancy.

The fetuses shared a placenta but were in separate amniotic sacs. This condition is referred to as monochorionic diamniotic twins. It arises when the blastocyst divides between the $3^{\text {rd }}$ and $8^{\text {th }}$ gestational days and is the most common type of monozygotic twins (Fox, 2006). Cases similar to the present one have been described in tubal twin pregnancy (Erol et al., 2013). These twins have higher rates of fetal loss and growth discordance than dichorionic ones because of often precarious vascular anastomoses and unequal distribution of placental utility (Mascarenhas and Ghanaprabha, 2016). The death of one twin is consistent with this disadvantage. Accordingly, it is important to determine the amnionicity and chorionicity of the fetus to optimize care.

The most common presentation is abdominal pain with vaginal bleeding (Ghanbarzadeh et al., 2015). The present case was atypical in that there was no vaginal bleeding. Similar atypical cases have been reported (Indiran, 2016). Such atypical presentation may mimic other causes of acute abdomen, confuse diagnosis, delay treatment and lead to high morbidity and mortality (Sivalingam et al., 2011). Accordingly, twin tubal pregnancy should be considered a differential diagnosis in cases of persistent lower abdominal pain in amenorrheic women, even in the absence of vaginal bleeding. Most cases of ectopic pregnancy present in the first trimester, usually between the $5^{\text {th }}$ and $10^{\text {th }}$ weeks (Ghanbarzadeh et al., 2015), with only a few reaching the $11^{\text {th }}$ week (Panelli et a., 2015). The current case presented at almost 13 weeks, although the pain had started at about the $8^{\text {th }}$ week. Early presentation and diagnosis reduces the risk of rupture and maternal morbidity and mortality (Ghanbarzadeh et al., 2015).

The amazing observation in the present case is that despite the advanced gestation, the tube was not ruptured, only displaying slight leakage. Since the first report of unruptured twin tubal pregnancy by Santos et al (1986), there have been other reports in literature (Goswami et al., 2014). Tubal rupture is usually attributed to hemorrhagic necrosis consequent to trophoblastic invasion (Stock et al., 1991). The absence of overt rupture suggests that other factors are involved, including probably the location of the gestational sac. A pertinent observation in this case is that both twins were in the fimbrial region, which is relatively wide and may therefore accommodate a bigger conceptus before attaining the threshold for rupture. Identification of unruptured ectopic pregnancy is important as it provides an opportunity for tube preserving intervention (Goswami et al., 2014). Accordingly, whenever possible, effort should be made to diagnose ectopic pregnancy before tubal rupture.

Tubal twins are usually diagnosed by transvaginal ultrasound, markedly elevated hCG, laparoscopy (Ghanbarzadeh et al., 2015) and magnetic resonance imaging (Indiran, 2016). In the present case, one sac was diagnosed preoperatively by abdominal ultrasound while the second twin was diagnosed intraoperatively, and hCG levels were not determined. It is important that all the gestational sacs are identified and managed to minimize complications of inadvertent retention of ectopic products of conception. Another intriguing feature of the present case was that one fetus was viable. Since the first case of live unilateral tubal twin pregnancy by Gualandi et al (1994), several other cases have been described (Benn et al., 2016). This is important as it may influence the options of management surgical, medical or expectant (Sivalingam et al., 2011).

In conclusion, tubal twin ectopic pregnancy may occur in the absence of any overt risk factor, be located anywhere along the tube, show atypical late presentation, intact tubes and viable fetus. These features call for heightened index of suspicion and sagacity in management of amenorrheic women with abdominal pain. 


\section{REFERENCES}

1. Abi Khalil ED, Mufarrij SM, Moawad GN, Mufarrij IS. 2016. Spontaneous Bilateral Ectopic Pregnancy: A case report. J Reprod Med; 61: 306 - 308.

2. Adesule AR, Phougat VS, Jakhere SG, Saifee SS. 2010. Preoperative ultrasonic Diagnosis of spontaneous live tubal ectopic gestation. Bombay Hosp J; 52: 235 - 237.

3. Ajibade F, Kushanu E, Olumbori A. 2012. Pregnancy of unknown location and multiple fibroids in early pregnancy. Ultrasound Obs Gynae; 40: s1 p04.11.

4. Al - Quraan GA, Al - Taani MI, Nusair BM, El - Maasri A, Arafat MR, Khateeb MM. 2007. Spontaneous ruptured and intact bilateral tubal ectopic pregnancy. La Revue de Sante de la Mediterranee Orientale; 13: 972 - 974.

5. Almeida OD. 2011. Fimbrial ectopic pregnancy following tubal anastomosis. J Soc Lap Surg; 15: 539 - 541.

6. Benn R, Wheeler V, Keshi C. 2016. Spontaneous live twin ectopic pregnancy: A case report. WIMJ open; 3: 25 27.

7. Erol O, Karaca M, Erol MB, Caglar M, Gurses C. 2013. Spontaneous unilateral monochorionic diamniotic twin tubal pregnancy: case report. Turk Klin J Gynecol Obstet; 23: 131 - 133.

8. Fox TB. 2006. Multiple pregnancies: Determining chorionicity and amnionicity. Department of Radiologic Sciences Faculty Papers. Paper 1. http://jdc.jefferson.edu/rsfp/1.

9. Garg MK, Vyas S, Gulati A, Galwa RP, khandelwal N. 2009. Primary ovarian pregnancy: Case Report and Review of the literature. J Clin Ultrasound; 37: $43-46$.

10. Ghanbarzadeh N, Nadjafi - Semnani M, Nadjfai - Semmani F, Shahabinejad S. 2015. Unilateral twin tubal ectopic pregnancy in a patient following tubal surgery. J Res Med Sci; 20: $196-198$.

11. Goswami D, Agrwal N, Arora V. 2015. Twin tubal pregnancy: A large unruptured ectopic pregnancy. J Obs Gynaecol Res; 41: 1820 - 1822.

12. Gualandi M, Steemers N, de Keyser JL. 1994. First reported case of preoperative ultrasonic diagnosis and laparoscopic treatment of unilateral twin tubal pregnancy. Rev Fr Gynaecol Obstet; 89: 134 - 136.

13. Indiran V. 2016. Acute pelvic pain in female ruptured ectopic pregnancy. Magnetic resonance imaging as a problem solving tool. Turk J Emerg Med; 16: 89 - 90.

14. Lin EP, Bhatt S, Dogra VS. 2008. Diagnostic clues to ectopic pregnancy. Radiographics; 28: 1661 - 1671.

15. Makinde OO, Ogunniyi SO. 1990. Bilateral tubal and twin pregnancies in Ile - Ife, Nigeria. Int J Gynecol Obstet; 33: $365-367$.

16. Mascarenhas M, Ghanaprabha K. 2016. Monozygotic pregnancies following assisted reproductive technology: A review. EMJ Repro Health; 2: 79 - 85.

17. Mpogoro FJ, Gumodoka B, Kihunrwa A, Massinde AN. 2013. Managing a live advanced abdominal Twin Pregnancy. Ann Med Health Sci Res; 3: 113 - 115.

18. Panelli DM, Phillips CH, Bady PC. 2015. Incidence, diagnosis and management of tubal and non tubal pregnancies: a review. Fertility Research Pract; 1: 15.

19. Pascual MA, Ruiz J, tressera F, Sanuy C, Grasses PJ, Tur R et al. 2001. Cervical ectopic twin pregnancy: diagnosis and conservative treatment: Case Report. Human Reprod; 16: 584 - 586.

20. Pulei AN, Muga PA, Ongeti KW, Ogutu O, Kinuthia J. 2017. Unilateral spontaneous tubal twin ectopic pregnancy: A rare occurrence. Anat J Afr; 6: $820-823$.

21. Ragsdale ES, Rosner M, Gebb J, Biraj E, Dar P. 2014. Twin interstitial ectopic pregnancy: a case report. Uultrasound Obs Gyne; 44: 339 - 340.

22. Santos CA, Sicuranza BS, Chetterjee MS. 1986. Twin tubal gestation diagnosed before rupture. Perinatol Neonatal; 10: $52-53$.

23. Sivalingam VN, Duncan WC, Kurk E, Shephard LA, Horne AW. 2011. Diagnosis and management of ectopic pregnancy. J Fam Plann Reprod Health Care; 37: 231 - 240.

24. Stock RJ. 1991. Tubal pregnancy. Associated histopathology. Obstet Gynecol Clin North Am; 18: 73 - 94.

25. Svirsky R, Maymon R, Vakmin Z, Mendlovic S, Weissman A, Halperin R et al., 2010. Twin tubal pregnancy: a rising complication. Fertility and Sterility; 94: 1910e13 - 16.

26. Vohra S, Mahsood S, Shelton H, Zaedi K, Economides DL. 2014. Spontaneous live unilateral twin ectopic pregnancy - A case presentation. Ultrasound; 22: $243-246$. 